\title{
Effect of Soya Lecithin on Solubilization and Biodegradation of Pentachlorophenol by Anthracophyllum discolor
}

\author{
Mariela Bustamante ${ }^{1}$, Olga Rubilar ${ }^{1}$, María Cristina Diez ${ }^{2 *}$ \\ ${ }^{1}$ Environmental Biotechnology Center, Scientific and Technological Bioresource Nucleus (BIOREN), Temuco, Chile \\ ${ }^{2}$ Chemical Engineering Department, Universidad de La Frontera, Temuco, Chile \\ Email: ․mariela.bustamate@ufrontera.cl, olga.rubilar@ufrontera.cl, cristina.diez@ufrontera.cl
}

Received November 23, 2013; revised December 24, 2013; accepted January 5, 2014

Copyright (c) 2014 Mariela Bustamante et al. This is an open access article distributed under the Creative Commons Attribution License, which permits unrestricted use, distribution, and reproduction in any medium, provided the original work is properly cited. In accordance of the Creative Commons Attribution License all Copyrights @ 2014 are reserved for SCIRP and the owner of the intellectual property Mariela Bustamante et al. All Copyright (C 2014 are guarded by law and by SCIRP as a guardian.

\section{ABSTRACT}

The effect of soya lecithin (SL) on solubilization and biodegradation of pentachlorophenol (PCP) by Anthracophyllum discolor was evaluated. Besides, the PCP effect on critical micelle concentration (CMC) of SL and the effect of PCP and SL on the ligninolytic activity of $A$. discolor were evaluated. The PCP solubilization test was performed for 100, 200 and $400 \mathrm{mg} \cdot \mathrm{L}^{-1}$ with SL solution varying concentrations of ranging from $0 \mathrm{to} 0.9 \mathrm{~g} \cdot \mathrm{L}^{-1}$. The effect of PCP (5 to $\left.20 \mathrm{mg} \cdot \mathrm{L}^{-1}\right)$ on CMC of SL by conductivity was evaluated. The effect of SL $\left(0 \mathrm{to} 0.9 \mathrm{~g} \cdot \mathrm{L}^{-1}\right)$ on biodegradation of PCP (21.4 mg. $\left.\mathrm{L}^{-1}\right)$ in modified Kirk medium was studied. The results showed that SL addition enhanced PCP solubility in water. The solubilities of 100, 200 and $400 \mathrm{mg} \cdot \mathrm{L}^{-1}$ of PCP were about 4.2, 5.0 and 2.5 times higher than their solubility in pure water when the system was added with $0.9 \mathrm{~g} \cdot \mathrm{L}^{-1} \mathrm{of} \mathrm{SL}$. We found that the increase in PCP concentration caused a decrease in the CMC value. In the biodegradation assay, in liquid medium supplemented with $0.9 \mathrm{~g} \cdot \mathrm{L}^{-1}$ of SL, the $94.4 \%$ of PCP was biodegraded after 26 days of incubation. In contrast, in the control assay (without SL), the 76.5\% of PCP was removed. The PCP degradation was confirmed by the presence of its metabolites. During biodegradation assay, $A$. discolor mainly produced manganese peroxidase reaching a maximum of $96.8 \mathrm{U} \cdot \mathrm{g}^{-1}(\mathrm{dw})$ when the culture medium was added with $0.6 \mathrm{~g} \cdot \mathrm{L}^{-1} \mathrm{of} \mathrm{SL}$. These results show that SL can be applied to increasing the bioavailability and biodegradation of PCP.

\section{KEYWORDS}

Soya Lecithin; Solubility; Biodegradation; White-Rot Fungi; Pentachlorophenol

\section{Introduction}

In the past, pentachlorophenol (PCP) was used for the protection and the preservation of wood, as an antifungal agent in the leather industry and as wide-spectrum biocide in industry and agriculture. This fact has led the groundwater, sediments and soil contamination with PCP due to its molecular stability and sorption properties [1]. Besides, the exposition to PCP-contaminated soil can result in dermal absorption, which can have adverse health effects [2].

The PCP is a weak acid with a pKa of 4.75 , low water solubility $\left(14 \mathrm{mg} \cdot \mathrm{L}^{-1}\right.$ at $\left.25^{\circ} \mathrm{C}\right)$, and high $\mathrm{K}_{\mathrm{OW}}\left(1.0 \times 10^{5}\right)$

"Corresponding author.
[3]. Therefore, PCP adsorbs on the organic fraction of soils [4] and can be present as non-aqueous phase liquids due to its low solubility in water [5]. Although PCP persists in many environments, biological methods have been utilized in groundwater and soil for the PCP bioremediation $[1,6]$.

Biodegradation process of PCP by white-rot fungi is well-known. Bjerkandera adusta, Phanerochaete chrysosporium, Trametes versicolor, and Trametes hirsute are some of the white-rot fungi that show the ability to degrade several contaminants, including PCP [7-10]. The potential of these microorganisms resides in its extracellular enzymatic systems, which may include lignin peroxidase $(\mathrm{LiP})$, manganese peroxidase $(\mathrm{MnP})$, and lac- 
case (Lac) [11,12]. Several studies have led to finding native fungal strains with ligninolytic activity and capacity to degrade several contaminants. Studies realized by Rubilar et al. [6,10] and Tortella et al. [13] have demonstrated that Anthracophyllum discolor, a native Chilean fungus, presents the ligninolytic activity with high level of MnP production and capacity to degrade PCP. However, these processes are negatively affected by the low water solubility of the contaminants, limiting their availability to microorganisms. Several researchers have reported that the addition of surfactant in contaminated sites increases the bioavailability of hydrophobic compounds, allowing an increase of its concentration in the water phase and, therefore, more available for biodegradation [14-16].

Surfactants are organic molecules with a hydrophilic group and a hydrophobic chain [17,18]. An important characteristic of these molecules is the formation of micelles, which are capable of dissolving hydrophobic compounds in their hydrophobic core, resulting in an apparent increment of its aqueous solubility $[19,20]$. Solubilization depends on the type and dose of the surfactant, and hydrophobic compound properties. Doong and Lei [21] evaluated the solubilization of four polycyclic aromatic hydrocarbons (PAHs) in a soil system in the presence of different surfactants. They found that the solubility of contaminants enhances with the addition of surfactant and the extent of availability depended on the polyoxyethylene chain present in the surfactant. Besides, Zhu and Feng [14] demonstrated that the PAHs are solubilized synergistically in mixed anionic-nonionic surfacetant solution, especially at low surfactant concentration. Shin et al. [22] examined the effect of $\mathrm{pH}$ on phenanthrene solubilization from soil in presence of rhamnolipid, an anionic biosurfactant produced by Pseudomonas. Their results showed that the solubility of the contaminant enhanced in a $\mathrm{pH}$ range of 4.5 - 5.5. Moreover, they concluded that the changes in the apparent solubility of the compound within the $\mathrm{pH}$ are attributed to the different $\mathrm{pH}$-depended structures of rhamnolipid. Cort et al. [23] evaluated the solubility of PCP in minimal medium containing Tergitol NP-10 (nonionic surfactant) adjusted to $\mathrm{pH}$ 2. They found that PCP concentration increased linearly as surfactant was added in the range of 50 - 1256 $\mathrm{mg} \cdot \mathrm{L}^{-1}$. On the other hand, Hanna et al. [24] determined that the apparent solubility of PCP increases linearly with catioinic surfactant concentration at $\mathrm{pH} 3$.

Soya lecithin (SL) is a slightly studied phytogenic surfactant on solubilization and biodegradation processes. It has been applied to studying its effects on biodegradation of PAHs and polychlorinated biphenyls. In this context, Soeder et al. [25] evaluated the effect of SL and quillaya saponin on the aerobic biodegradation of PAHs in shakebatch cultures of bacteria. Their results showed that SL has high PAH-solubilizing activity and a lower bacterial toxicity with respect to quillaya saponin.

In general, biosurfactants are considered as low or non-toxic [26]. However, it can be toxic and exert inhibitory effects on the biodegrading microorganisms [27,28]. Flasz et al. [29] found that the chemical surfactant presented higher toxicity and mutagenic effects, whereas that the natural surfactants were less-toxic and non-mutagenic. Soeder et al. [25] established that SL enhances growth of bacteria. Besides, Bustamante et al. [30] demonstrated that when SL is included in the growth medium, it enhances growth and $\mathrm{MnP}$ production of A. discolor. In this context, scanning electron microscopy (SEM) is a useful tool for exploring the surface of microorganisms and detecting the biosurfactant effect.

The potential of SL for enhancing the solubility of hydrophobic organic compounds, its low toxicity on the degrader microorganisms, the capability of $A$. discolor to produce $\mathrm{MnP}$ and to degrade PCP suggest the opportunity to study the effect of SL on the solubilization and biodegradation of PCP by A. discolor in liquid medium. Besides, the effect of several PCP concentrations on critical micelle concentration of SL and the effect of SL on A. discolor surface by SEM were evaluated.

\section{Materials and Methods}

\subsection{Microorganism and Growth Conditions}

The white-rot fungus Anthracophyllum discolor was obtained from the culture collection of the Environmental Biotechnology Laboratory of the Universidad de La Frontera (Chile). The fungus was transferred from slant tubes to glucose malt extract agar plates (per liter of distilled water) $15 \mathrm{~g}$ agar, $10 \mathrm{~g}$ glucose, $30 \mathrm{~g}$ malt extract, $\mathrm{pH} 5.2$, maintained at $4^{\circ} \mathrm{C}$ in plate and then incubated at $26^{\circ} \mathrm{C} \pm 2{ }^{\circ} \mathrm{C}$ for 7 days before being used for inoculum preparation.

\subsection{Preparation of the Blended Mycelium}

A. discolor was first grown in 1-L Erlenmeyer flask containing $100 \mathrm{~mL}$ of modified Kirk medium [31] and five 6-mm diameter agar plugs of active mycelium. The culture was incubated statically at $26^{\circ} \mathrm{C} \pm 2{ }^{\circ} \mathrm{C}$ for 7 days in darkness. After this, the fungal culture was homogenized in a sterilized blender for 1 min. The modified Kirk medium contained (per liter of distilled or deionized water) 10 g glucose, 0.12 g C $_{4} \mathrm{H}_{12} \mathrm{~N}_{2} \mathrm{O}_{6}, 2 \mathrm{~g} \mathrm{KH}_{2} \mathrm{PO}_{4}, 0.59 \mathrm{~g}$ $\mathrm{MgSO}_{4} \cdot 7 \mathrm{H}_{2} \mathrm{O}, 0.1 \mathrm{~g} \mathrm{CaCl}_{2}, 3.3 \mathrm{~g} \mathrm{CH}_{3} \mathrm{COONa} \cdot 3 \mathrm{H}_{2} \mathrm{O}$ and $10 \mathrm{~mL}$ mineral salts. The initial $\mathrm{pH}$ of the medium was adjusted to 5.5 with either $1 \mathrm{M} \mathrm{NaOH}$ or $1 \mathrm{M} \mathrm{HCl}$.

\subsection{Chemicals and Stock Solutions Preparation}

The 2,4-dicholorophenol (2,4-DCP) was obtained from 
Sigma-Aldrich and 2,4,6-trichlorophenol (2,4,6-TCP) was purchased from Fluka. Pentachlorophenol (PCP) was obtained from Aldrich Chemical Co., with $>98 \%$ purity. The other compounds were greater than 97\% purity. Soya lecithin (SL) was purchased from PRINAL ${ }^{\circledR}$. The N and organic $\mathrm{C}$ contain were $1.04 \%$ and $56.41 \%$ measured by Kjeldahl and Total Organic Carbon (TOC- $\mathrm{V}_{\mathrm{CPH}}$, Shimadzu), respectively.

\subsection{The PCP Solubilization Test}

The solubility test was performed in a $20-\mathrm{mL}$ glass tube. An aliquot of PCP stock solution (5 $\mathrm{g} \cdot \mathrm{L}^{-1}$ in acetone) to reach a final concentration of 100,200 and $400 \mathrm{mg} \cdot \mathrm{L}^{-1}$ was added to each tube. After evaporating the acetone, aliquots of SL stock solution (50 g. $\mathrm{L}^{-1}$ in water) ranging from 0 to $0.9 \mathrm{~g} \cdot \mathrm{L}^{-1}$ was added to each tube. The tubes were homogenized in a mechanical shaker for $24 \mathrm{~h}$ at $150 \mathrm{rpm}$ and $25^{\circ} \mathrm{C} \pm 2^{\circ} \mathrm{C}$. After this time, the samples were centrifuged for $15 \mathrm{~min}$ at $3000 \mathrm{rpm}$ to separate the undissolved portion of PCP. Then supernatants were filtered through $0.2 \mu \mathrm{m}$ diameter pore. The PCP was quantified by high performance liquid chromatography (HPLC). Triplicates tube were run for each concentration.

\subsection{Effect of PCP on Critical Micelle Concentration of SL}

The effect of PCP on critical micelle concentration (CMC) of SL in modified Kirk medium was determined by the breakpoint of conductivity versus surfactant concentration curve. The assay was performed in $100-\mathrm{mL}$ Erlenmeyer flask with $50 \mathrm{~mL}$ of modified Kirk medium and aliquots of SL concentration ranged from 0.2 to $2 \mathrm{~g}$. $\mathrm{L}^{-1}$ were added. After this, aliquots of PCP stock solution $\left(1 \mathrm{~g} \cdot \mathrm{L}^{-1}\right.$ in deionized water and adequate quantity of $1 \mathrm{~N}$ $\mathrm{KOH}$ to dissolve PCP) to obtain a final concentration of 5, 10, 15 and $20 \mathrm{mg} \cdot \mathrm{L}^{-1}$ were added. The electrical conductivity of each solution was measured with a $\mathrm{HACH}$ Sens ion 5 conductivimeter at $25^{\circ} \mathrm{C} \pm 2^{\circ} \mathrm{C}$. The results of CMC are reported as the mean of three replicates.

\subsection{Effect of SL on PCP Biodegradation by A. discolor in Liquid Medium}

Effect of SL on PCP biodegradation by A. discolor was evaluated using $10 \mathrm{~mL}$ of modified Kirk medium in 100-mL Erlenmeyer flask. An aliquot of PCP stock solution (5 g. $\mathrm{L}^{-1}$ in acetone) and SL stock solution (50 g. $\mathrm{L}^{-1}$ in hexane) were aseptically added to a sterile Erlenmeyer flask to give a final concentration of approximately 20 $\mathrm{mg} \cdot \mathrm{L}^{-1}$ of PCP and $0,0.3,0.6$, or $0.9 \mathrm{~g} \cdot \mathrm{L}^{-1}$ of SL. Then, organic solvents were evaporated for re-crystalization of SL and PCP under aseptic conditions. After this, each Erlenmeyer flask received an inoculum of A. discolor (10
$\mathrm{mL}$ of modified Kirk medium and $0.4 \mathrm{~mL}$ of blended mycelium of $A$. discolor). The flasks were incubated under static conditions in darkness for 26 days at $26^{\circ} \mathrm{C} \pm$ $2^{\circ} \mathrm{C}$. PCP and its metabolites (2,4-DCP and 2,4,6-TCP) were quantified periodically $(1,5,10,15$, and 26 days) in the liquid medium and in the fungal mycelium by HPLC. Besides, enzymatic activities of Lac, MnP, lignin peroxidase (LiP) and manganese-independent peroxidase (MiP) and $\mathrm{pH}$ variation were evaluated.

\subsection{Effect of SL on A. discolor Surface Visualized by Electronic Microscopy}

The scanning electron microscopy (SEM) was used for detecting some SL effect on the surface of $A$. discolor. An aliquot of SL stock solution (50 g. $\mathrm{L}^{-1}$ in hexane) was added in to a sterile 100-mL Erlenmeyer flask to give a final concentration of $0.6 \mathrm{~g} \cdot \mathrm{L}^{-1}$. After hexane was evaporated, each flask was inoculated with $A$. discolor. Biotic control (liquid medium with SL and $A$. discolor) was established in parallel. Each experiment was carried out under destructive sampling mode. All flasks were incubated at $26^{\circ} \mathrm{C} \pm 2^{\circ} \mathrm{C}$ in darkness for 20 days. The fungal surface of $A$. discolor was visualized by SEM after 5 and 20 days of incubation. The analyses were carried out with a Jeol JSM-6360LV microscope.

\subsection{Analytical Procedures}

\subsubsection{Determination of Enzymatic Activities in the Liquid Medium}

The enzymatic activities (Lac, LiP, MiP and MnP) were measured from the supernatant of a previously centrifuged sample (2 min at $3000 \mathrm{rpm}$ ) of liquid medium.

Laccase activity was determined with 2,6-dimethoxxyphenol (2,6-DMP) as the substrate in sodium malonate (pH 4.5). The enzyme activity unit was defined as an increase in absorbance per minute at $468 \mathrm{~nm}$ and $30^{\circ} \mathrm{C}$ [32]. MnP activity was determined by monitoring the oxidation of 2,6-DMP spectrophotometrically at $30^{\circ} \mathrm{C}$. The reaction mixture $(1 \mathrm{~mL})$ contained $200 \mu \mathrm{L}$ of 250 $\mathrm{mM}$ sodium malonate $(\mathrm{pH} 4.5), 50 \mu \mathrm{L}$ of $20 \mathrm{mM}$ 2,6-DMP, $50 \mu \mathrm{L}$ of $20 \mathrm{mM} \mathrm{MnSO}{ }_{4} \cdot \mathrm{H}_{2} \mathrm{O}$ and $600 \mu \mathrm{L}$ of supernatant. The reaction was initiated by adding $100 \mu \mathrm{L}$ of $4 \mathrm{mM} \mathrm{H} \mathrm{H}_{2}$, monitored at $468 \mathrm{~nm}$ and corrected by Lac activity. MiP activity was determined in a reaction mixture containing $200 \mu \mathrm{L}$ of $250 \mathrm{mM}$ sodium malonate (pH 4.5), $50 \mu \mathrm{L}$ of $20 \mathrm{mM}$ 2,6-DMP, $100 \mu \mathrm{L}$ of $20 \mathrm{mM}$ EDTA, and $600 \mu \mathrm{L}$ of supernatant. This reaction was initiated by adding $100 \mu \mathrm{L}$ of $4 \mathrm{mM} \mathrm{H}_{2} \mathrm{O}_{2}$, monitored at $468 \mathrm{~nm}$ and corrected by the Lac activity [32]. The molar extinction coefficient was $49,600 \mathrm{M}^{-1} \cdot \mathrm{cm}^{-1}$.

LiP activity is based on the oxidation of veratryl alcohol. The reaction mixture contained $1420 \mu \mathrm{L}$ disodium tartrate dihydrate $(0.1 \mathrm{M}, \mathrm{pH} 3.0), 400 \mu \mathrm{L}$ veratryl alco- 
hol $(20 \mathrm{mM})$ and $100 \mu \mathrm{L}$ of supernatant. The reaction was initiated by adding $80 \mu \mathrm{L}$ of $\mathrm{H}_{2} \mathrm{O}_{2}(10 \mathrm{mM})$ [33] and was monitored at $310 \mathrm{~nm}$ for $2 \mathrm{~min}$. The molar extinction coefficient was $93,000 \mathrm{M}^{-1} \cdot \mathrm{cm}^{-1}$. The absorbance was read using Spectronic Genesys 2PC model spectrophotometer and expressed in $\mathrm{U} \cdot \mathrm{g}^{-1}$ dry weight $\left(\mathrm{U} \cdot \mathrm{g}^{-1} \mathrm{dw}\right)$ of mycelium.

\subsubsection{Extraction and Quantification of PCP from the Liquid Medium and Fungal Mycelium}

The liquid medium and fungal mycelium of A. discolor were vacuum-filtered through $0.2 \mu \mathrm{m}$ pore size of nitrocellulose membrane. The filtered liquid medium was analyzed by HPLC. The biomass retained in the membrane was transferred to $100-\mathrm{mL}$ Erlenmeyer flasks, diluted with $5 \mathrm{~mL}$ hexane:acetone mixture (1:1) and adjusted at $\mathrm{pH} 2$ with $0.1 \mathrm{~N} \mathrm{H}_{2} \mathrm{SO}_{4}$. The Erlenmeyer flasks were hermetically sealed and shaken for $2 \mathrm{~h}$ at $150 \mathrm{rpm}$. After shaking, Erlenmeyer flasks were taken to a sonic bath for $30 \mathrm{~min}$. The mixture was vacuum-filtered through $0.22 \mu \mathrm{m}$ pore size of polytetrafluoroethylene membrane. The retained biomass was dried at $105^{\circ} \mathrm{C}$ for $3 \mathrm{~h}$ to determine dry weight. The extract of PCP adsorbed in fungal mycelium was analyzed by HPLC.

The PCP concentrations were quantified by HPLC with a Merck Hitachi L-7100 pump, a Rheodyne 7725 injector with $20 \mu \mathrm{L}$ loop diode array detector. The column was a reverse phase (Lichrosphere 60RP select $\mathrm{B}, 5$ $\mu \mathrm{m})$. Detection of PCP and metabolites (2,4-DCP and 2,4,6-TCP) were at $210 \mathrm{~nm}$ and the mobile phase consisted of $1 \%$ phosphoric acid/acetonitrile (40:60, v/v). Determinations were with a flow rate of $1 \mathrm{~mL} \cdot \mathrm{min}^{-1}$, at room temperature $\left(22^{\circ} \mathrm{C} \pm 2^{\circ} \mathrm{C}\right)$. The presence of surfactant, SL, did not interfere with the detection of PCP and their metabolites. The procedure described was checked for PCP recovery (which ranged from $94 \%$ to $100 \%$ ). The retention time were 3.79, 4.49 and $6.11 \mathrm{~min}$ for 2,4DCP, 2,4,6-TCP and PCP, respectively.

\subsubsection{Preparation and Inspection of Mycelium of $A$. discolor for SEM}

Mycelium of $A$. discolor for SEM was obtained from cultures with 5 and 20 days of incubation. The mycelium sample was centrifuged at room temperature by $15 \mathrm{~min}$ at $4000 \mathrm{rpm}$. After this, the mycelium was fixed with a $2 \%$ $\mathrm{v} / \mathrm{v}$ glutaraldehyde in $0.1 \mathrm{M}$ potassium phosphate buffer (pH 7) for $18 \mathrm{~h}$ at $4^{\circ} \mathrm{C}$. Then, mycelium was centrifuged (15 min at $4000 \mathrm{rpm}$ at room temperature) and washed three times with distilled water in $30 \mathrm{~min}$. Afterwards, the mycelium sample was fixed with a $4 \% \mathrm{v} / \mathrm{v}$ osmium tetraoxide in $0.1 \mathrm{M}$ potassium phosphate buffer $(\mathrm{pH} 7)$ for $2 \mathrm{~h}$ at room temperature. Besides this treatment, the samples were dehydrated by immersion in ascending series solution of ethanol (70\%, 80\%, 90\%, and 100\%).
Apart from this treatment, the mycelium was washed with potassium phosphate buffer $(\mathrm{pH} \mathrm{7)}$ for $30 \mathrm{~min}$ followed by three changes with distilled water. Finally, the mycelium was re-suspended in distilled water, and a drop of suspension was deposited over coverslips and air-dried overnight at room temperature. The completely dried mycelium was coated with $\mathrm{Au} / \mathrm{Pd}$ with BAL-TEC to make observations using a scanning electron microscope.

\subsubsection{Quantification of Fungal Biomass}

The fungal biomass was determined by measuring the dry weight of fungal mycelium. The culture medium was vacuum-filtered through a $0.22 \mu \mathrm{m}$ pore size of nitrocellulose membrane. The retained biomass was dried at $105^{\circ} \mathrm{C}$ until reaching a constant weight. The yield was expressed as $\mathrm{g}$ dry weight of mycelium $\mathrm{L}^{-1}$ of liquid medium.

\section{Results and Discussion}

\subsection{The PCP Solubilization Test}

The effect of SL on the aqueous solubility of PCP was evaluated by test tube solubilization assays in the presence of increasing concentrations of SL $\left(0.3\right.$ to $\left.0.9 \mathrm{~g} \cdot \mathrm{L}^{-1}\right)$. In general, the concentration of solubilized PCP in the SL solutions increased with the addition of SL (Figure 1). The PCP solubility in pure water, without SL, reached values of $16.2,15.0$ and $24.0 \mathrm{mg} \cdot \mathrm{L}^{-1}$ when PCP concentrations were 100,200 and $400 \mathrm{mg} \cdot \mathrm{L}^{-1}$, respectively. The contaminant solubility enhanced slowly when SL increased at $0.3 \mathrm{~g} \cdot \mathrm{L}^{-1}$, reaching values between 20.8 and $24.8 \mathrm{mg} \cdot \mathrm{L}^{-1}$. An increase of solubility was observed with $0.6 \mathrm{~g} \cdot \mathrm{L}^{-1}$ of $\mathrm{SL}$, reaching values of $48.8,33.4$ and 35.8 $\mathrm{mg} \cdot \mathrm{L}^{-1}$ in presence of 100,200 and $400 \mathrm{mg} \cdot \mathrm{L}^{-1}$ of PCP, respectively. Finally, PCP solubility with $0.9 \mathrm{~g} \cdot \mathrm{L}^{-1}$ of SL were about 4.2, 5.0 and 2.5 folds higher than the pure water solubilities for 100,200 and $400 \mathrm{mg} \cdot \mathrm{L}^{-1}$ of initial concentration of PCP, respectively.

Besides, when PCP initial concentration was of 100

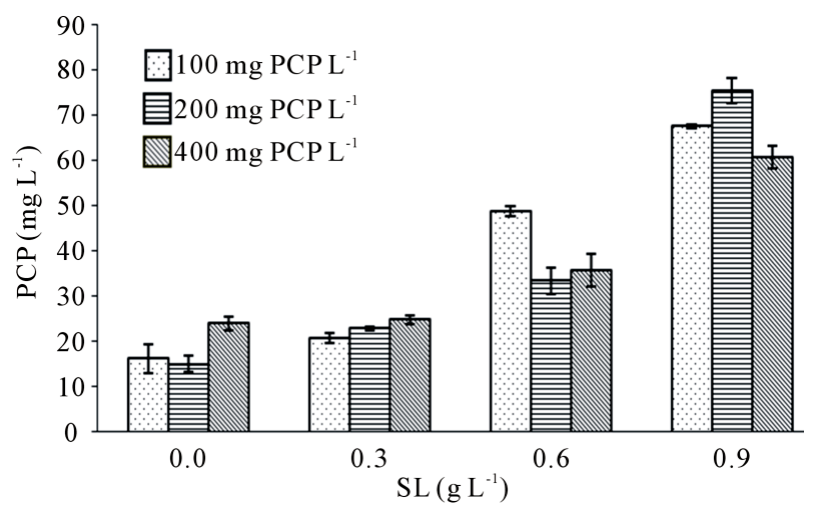

Figure 1. Solubilization of PCP by SL solutions prepared with distilled water, at $25^{\circ} \mathrm{C} \pm 2^{\circ} \mathrm{C}$ and $\mathrm{pH}$ 5.5. The values are expressed as mean of three replicate \pm SD. 
$\mathrm{mg} \cdot \mathrm{L}^{-1}$, the concentration of PCP solubilized increased linearly with SL addition and the relationship was given by the equation $y=60.7 x+11.0\left(R^{2}=0.94\right)$, where $x$ is the SL concentration and $y$ is solubilized PCP (Table 1 ). When the PCP initial concentration was of 200 and 400 $\mathrm{mg} \cdot \mathrm{L}^{-1}$, values of $\mathrm{R}^{2}$ were 0.85 and 0.83 , respectively. The effectiveness of a surfactant in solubilizing a given solute is known as the molar solubilization ratio. The molar solubilization ratio is defined as the number of moles of the compound solubilized per number of moles of surfactant added to the solution, and can be experimentally determined as of slop of the curve solute concentration vs. surfactant solution [19]. In this context, the effectiveness of SL for $100 \mathrm{mg} \cdot \mathrm{L}^{-1}$ of PCP was 60.72 $\mathrm{mg} \cdot \mathrm{g}^{-1}$. Besides, the effectiveness of SL was to 63.94 and 40.35 when the PCP concentration increases to 200 and $400 \mathrm{mg} \cdot \mathrm{L}^{-1}$ for $\mathrm{R}^{2}$ of 0.85 and 0.83 , respectively. Edwards et al. [19] evaluated the solubility of PAH in nonionic surfactant solution. Their result demonstrated that the solubility of PAH increases linearly with surfactant concentration above the CMC, similar to the results above presented.

The result shows that SL had certain effect on the solubilization of PCP either below or above its CMC, 0.61 $g \cdot \mathrm{L}^{-1}$ [30]; the solubilization was higher than when the SL concentration was above its CMC. Similar result was reported by Eddouaouda et al. [34]. They found that the solubility of phenanthrene in water was higher when the biosurfactant concentration was above its CMC. This situation can be explained due to that surfactant molecules exist as monomers below its CMC and, as was described by Eddouaouda et al. [34] and Li and Chen [35] monomeric molecules have minimal partition effect on solute. In contrast, contaminant solubility is increased when surfactant concentration is above its CMC. On the other hand, Cort et al. [23] evaluated the aqueous solubility of PCP in the presence of surfactant nonionic, Tergitol NP-10. They found that PCP concentration increased linearly as surfactant was added. Garon et al. [36] quantified the extent of fluorene solubilization in presence of three surfactants. Their results showed that fluorine dissolution was increased in the presence of surfactant, and the increasing solubility was dependent on the type of surfactant. They obtained higher solubilization

Table 1. The effect of SL on aqueous solubility of three initial PCP concentrations in water-SL system.

\begin{tabular}{ccc}
\hline $\begin{array}{c}\text { Initial PCP } \\
\text { concentration } \\
\left(\mathbf{m g} \cdot \mathbf{L}^{-1}\right)\end{array}$ & Experimental equation & $\mathbf{R}^{\mathbf{a}}$ \\
\hline 100 & $\mathrm{y}=60.72 \mathrm{x}+11.01$ & 0.94 \\
200 & $\mathrm{y}=63.94 \mathrm{x}+7.91$ & 0.85 \\
400 & $\mathrm{y}=40.35 \mathrm{x}+18.14$ & 0.83 \\
\hline
\end{tabular}

${ }^{a}$ Where $x$ is the SL concentration and $y$ is solubilized PC. with Tween 80 with respect to SDS. The effect of biosurfactants (produced by Pseudomona aeruginosa strains) on the solubility of polycyclic aromatic hydrocarbons was evaluated by Bordoli and Konwar [37]. They reported that solubility of contaminants was enhanced. Besides, it depended on contaminant and $P$. aeruginosa strains.

\subsection{Effect of PCP on CMC of SL}

Table 2 presents the effect of several PCP concentrations on CMC of SL. This Table shows that CMC value decreases as the concentration of PCP increases. In a previous study, we determined that CMC of SL in modified Kirk medium without PCP was $0.61 \mathrm{~g} \cdot \mathrm{L}^{-1}$ [30]. However, the CMC of surfactant depends on many factors, such as determination method [38,39], phospholipid composition, electrolyte addition, solution temperature, presence of organic additives [40] or conditions of salinity [41], among other; making this value different from the one determined in pure water [39].

As reported in literature, the CMC value decreases as the concentration of solute increases [42]. This result can be due to a neutralization of the surface charge of the surfactant by the contaminant, affecting the micelle formation. A reduction of the thickness of the ionic atmosphere around the surfactant ionic heads, produce electrostatic repulsions between them, helping in this way the micellization process. This behavior is followed by all kinds of surfactants, independent from their chemical nature [39].

\subsection{Effect of SL on Biodegradation of PCP by A. discolor in Liquid Medium}

A variety of surfactants have been applied for the biodegradation of compound with low solubility in liquid medium, groundwater aquifers, and contaminated soils, among others. Nevertheless, few studies have addressed the removal of these compounds using phytogenic surfactant, as SL, in combination with white-rot fungi. In this context, the SL effect on the PCP degradation by $A$. discolor in liquid medium was evaluated. Considering the lack of information about the SL effects on PCP biodegradation, SL was tested at concentrations of $0,0.3$, 0.6 , and $0.9 \mathrm{~g} \cdot \mathrm{L}^{-1}$, which were below and above the previously determined CMC $\left(0.6 \mathrm{~g} \cdot \mathrm{L}^{-1}\right)$.

The medium was contaminated with $21.4 \mathrm{mg} \cdot \mathrm{L}^{-1}$ of PCP. The degradation was established by both the removal of PCP (Table 3 ) and the production of metabolites, as 2,4-dicholorophenol (2,4-DCP) and 2,4,6-trichlorophenol (2,4,6-TCP) (Table 4). After 26 days of incubation, the $94.4 \%$ of PCP was removed, when the culture medium was supplemented with $0.9 \mathrm{~g} \cdot \mathrm{L}^{-1}$ of SL. In contrast, in the control assay (without SL) only the 76.5 
Table 2. The CMC of SL determined through electrical conductivity measurements in modified Kirk medium at pH 5.5 and $25^{\circ} \mathrm{C} \pm 2{ }^{\circ} \mathrm{C}$. Values of $\mathrm{CMC}$ are expressed as mean of three replicates \pm SD.

\begin{tabular}{|c|c|}
\hline PCP $\left(\mathrm{mg} \cdot \mathrm{L}^{-1}\right)$ & CMC $\left(g \cdot L^{-1}\right)$ \\
\hline 5 & $1.27 \pm 0.01$ \\
\hline 10 & $1.00 \pm 0.03$ \\
\hline 15 & $0.88 \pm 0.02$ \\
\hline 20 & $0.39 \pm 0.01$ \\
\hline
\end{tabular}

Table 3. Residual concentration of PCP $\left(\mathbf{m g} \cdot \mathrm{L}^{-1}\right)$ and removed PCP (\%) by A. discolor, in modified Kirk medium with several concentrations of $\mathrm{SL}$, at $\mathrm{pH} 5.5$ and $25^{\circ} \mathrm{C} \pm 2^{\circ} \mathrm{C}$, after 26 day of incubations ${ }^{\dagger}$.

\begin{tabular}{|c|c|c|c|}
\hline \multirow{2}{*}{$\mathrm{SL}\left(\mathrm{g} \cdot \mathrm{L}^{-1}\right)$} & \multicolumn{2}{|c|}{ Residual PCP $\left(\mathrm{mg} \cdot \mathrm{L}^{-1}\right)$} & \multirow{2}{*}{$\begin{array}{c}\text { Removed PCP } \\
(\%)\end{array}$} \\
\hline & Liquid medium & Mycelium & \\
\hline 0 & 3.5 & 1.6 & 76.5 \\
\hline 0.3 & 1.4 & 0.4 & 91.8 \\
\hline 0.6 & 1.2 & 0.5 & 92.2 \\
\hline 0.9 & 0.5 & 0.6 & 94.4 \\
\hline
\end{tabular}

${ }^{\dagger}$ Initial concentration of PCP $=21.4 \mathrm{mg} \cdot \mathrm{L}^{-1}$.

Table 4. Degradation products of PCP by A. discolor after 26 days of incubation. The metabolite concentrations are expressed as mean of three replicates \pm SD.

\begin{tabular}{|c|c|c|}
\hline SL $\left(g \cdot \mathrm{L}^{-1}\right)$ & 2,4-DCP $\left(\mathrm{mg} \cdot \mathrm{L}^{-1}\right)$ & 2,4,6-TCP $\left(\mathrm{mg} \cdot \mathrm{L}^{-1}\right)$ \\
\hline 0 & $1.0 \pm 0.1$ & - \\
\hline 0.3 & $1.4 \pm 0.2$ & - \\
\hline 0.6 & $2.0 \pm 0.3$ & - \\
\hline 0.9 & $3.7 \pm 0.1$ & $0.2 \pm 0.0$ \\
\hline
\end{tabular}

$\%$ of PCP was removed. These results show that the presence of SL improved PCP degradation by A. discolor. The PCP degradation with $0.9 \mathrm{~g} \cdot \mathrm{L}^{-1}$ of SL was $18 \%$ higher than control test. Similar results were obtained by Cort et al. [23]; they evaluated the effect of nonionic surfactant on PCP biodegradation. Their result showed a faster PCP degradation rates at higher concentrations of nonionic surfactant, Tergitol NP-10. These results can be explained by surfactant reducing the substrate inhibition. On the other hand, some studies have shown that the toxicity of PCP in white-rot fungi is not related to the concentration of contaminant in liquid medium, it is given by the dose, expressed as the ratio of the mass of chemical to the mass of the mycelium $[43,44]$. Nonionic surfactants, such as Tween 20, Tergitol NP-10, among others, are good candidates to enhance in situ remediation, based on their low biotoxicity and protective effect [45].

In relation to the residual concentration of PCP in the biomass mycelium (Table 3), the result shows that the increase in SL concentration caused an increase of the concentration of PCP in the biomass, $1.7 \%, 2.3 \%$ and $2.9 \%$ for
0.3, 0.6 and $0.9 \mathrm{~g} \cdot \mathrm{L}^{-1}$ of SL, respectively. This fact can be explained by that the surfactants may have an effect on the permeability of membrane for contaminants with low solubility in water, due to biological membranes present phospholipid equal that the surfactants [46]. However, in the control assay, without SL, the biomass sorption of PCP was greater than in presence of SL, and can explain the low percent of PCP removal (76.5\%). Besides, Table 3 shows that the percent of PCP removed increase with increase in SL concentration. In this context, the SL presence can eliminate the inhibitory effect of PCP.

On the other hand, the concentrations of metabolites in the culture medium were quantified after 26 days of incubations (Table 4). The highest concentration of metabolites of PCP was detected when the culture medium was supplemented with $0.9 \mathrm{~g} \cdot \mathrm{L}^{-1}$ of SL, with 3.7 of 2,4-DCP and $0.2 \mathrm{mg} \cdot \mathrm{L}^{-1}$ of 2,4,6-TCP. Besides, 2,4-DCP concentration increased when the SL concentration increased in liquid medium from 0 at $0.9 \mathrm{~g} \cdot \mathrm{L}^{-1} \mathrm{SL}$. However, the percent of metabolites produced was low respect to the PCP initial concentration and did not exceed the $10 \%$ for 2,4-DCP and 2,4,6-TCP when the SL concentration was from 0 to $0.6 \mathrm{~g} \cdot \mathrm{L}^{-1}$ and $0.9 \mathrm{~g} \cdot \mathrm{L}^{-1}$, respectively.

\subsection{Enzyme Production in the Presence of SL and PCP}

The enzymatic activity of $A$. discolor was evaluated during the PCP biodegradation assay. After 26 days, the amount of Lac produced did not exceed $4 \mathrm{U} \cdot \mathrm{g}^{-1}$ (Figure 2(a)). Besides, the highest $\mathrm{MnP}$ activities were detected at 26 days (Figure 2(b)). The $\mathrm{MnP}$ activity presented a maximum of $96.8 \mathrm{U} \cdot \mathrm{g}^{-1}$ when $0.6 \mathrm{~g} \cdot \mathrm{L}^{-1}$ of SL was incorporated into the culture medium (day 1 ). After this stage, MnP activity went down until $21.7 \mathrm{U} \cdot \mathrm{g}^{-1}$ (day 5). The MnP activity of $A$. discolor after of 26 days of incubation was 29.5, 37.1 and $42.2 \mathrm{U} \cdot \mathrm{g}^{-1}$ when liquid medium was added with $0.3,0.6$ and $0.9 \mathrm{~g} \cdot \mathrm{L}^{-1}$ of SL, respectively. A discolor only produced high levels of MiP when $0.6 \mathrm{~g} \cdot \mathrm{L}^{-1}$ of SL were added to liquid medium, reaching a maximum of $9.7 \mathrm{U} \cdot \mathrm{g}^{-1}$ at 26 days (Figure 2(c)). In

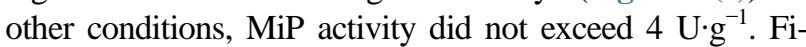
nally, LiP activity did not exceed $5.7 \mathrm{U} \cdot \mathrm{g}^{-1}$, date no shown.

\subsection{Variation of $\mathrm{pH}$ and Biomass in the Presence of SL and PCP}

The $\mathrm{pH}$ variation and biomass production are presented in Figure 3. After 26 days of incubation, the $\mathrm{pH}$ of liquid medium was between 5.2 and 5.7 units for all the conditions, with and without SL (Figure 3(a)). In this assays the initial concentration of biomass for the biodegradation test was $1.4 \mathrm{~g} \cdot \mathrm{L}^{-1}$ (Figure $3(\mathrm{~b})$ ). The PCP addition 


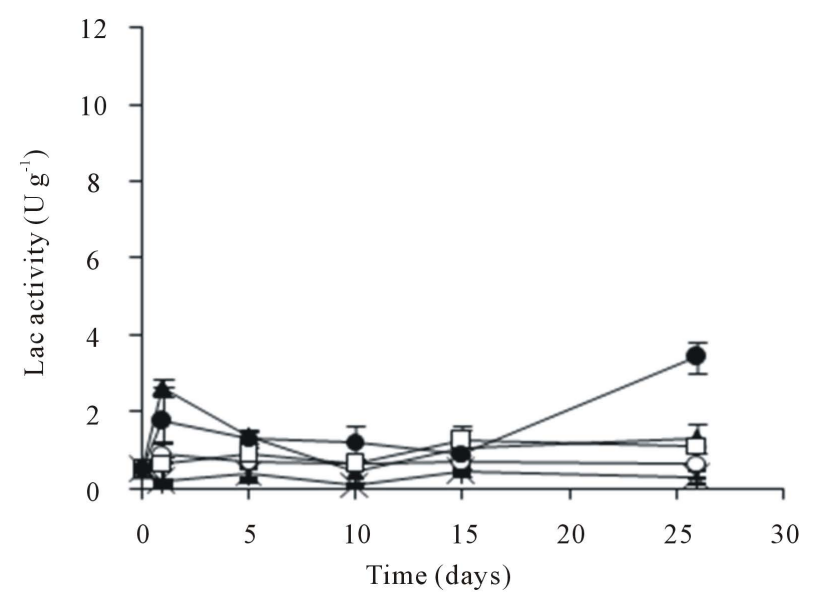

(a)

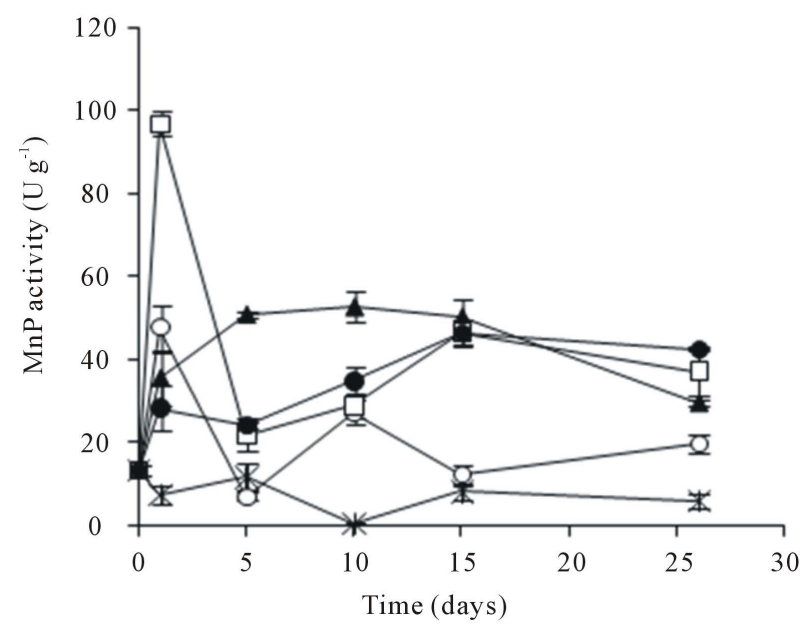

(b)

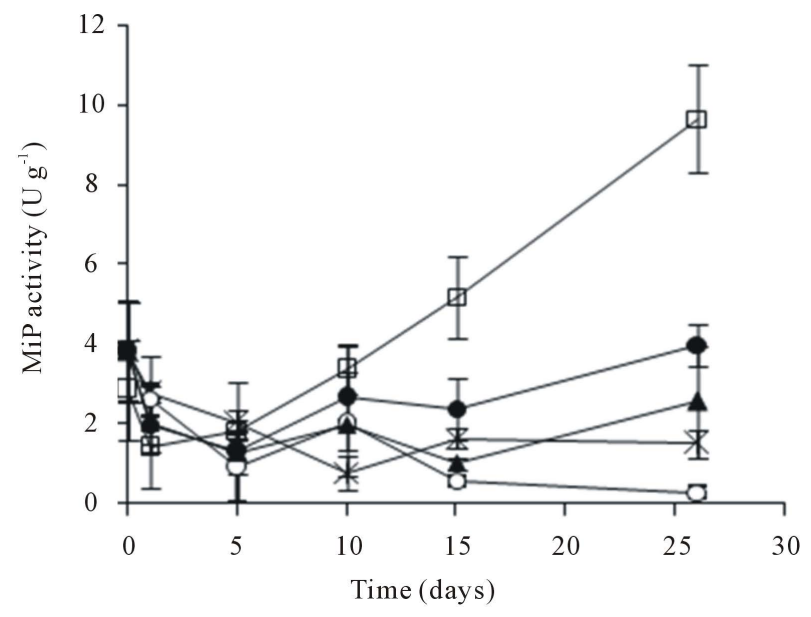

(c)

Figure 2. Effect of PCP and SL on the ligninolytic activity of $A$. discolor in liquid medium. (a) Lac activity, (b) MnP activity and (c) MiP activity. Values are expressed as mean of three replicates \pm SD. Where: $(*)$ A. discolor, $(\circ)$ A. discolor + PCP + $0 \mathrm{~g} \mathrm{SL} \cdot \mathrm{L}^{-1},(\Delta) A$. discolor + PCP + 0.3 g SL. $\mathrm{L}^{-1}$, (口) A. discolor + PCP + $0.6 \mathrm{~g} \mathrm{SL} \cdot \mathrm{L}^{-1},(\bullet)$ A. discolor + PCP + 0.9 g SL $\cdot \mathrm{L}^{-1}$.

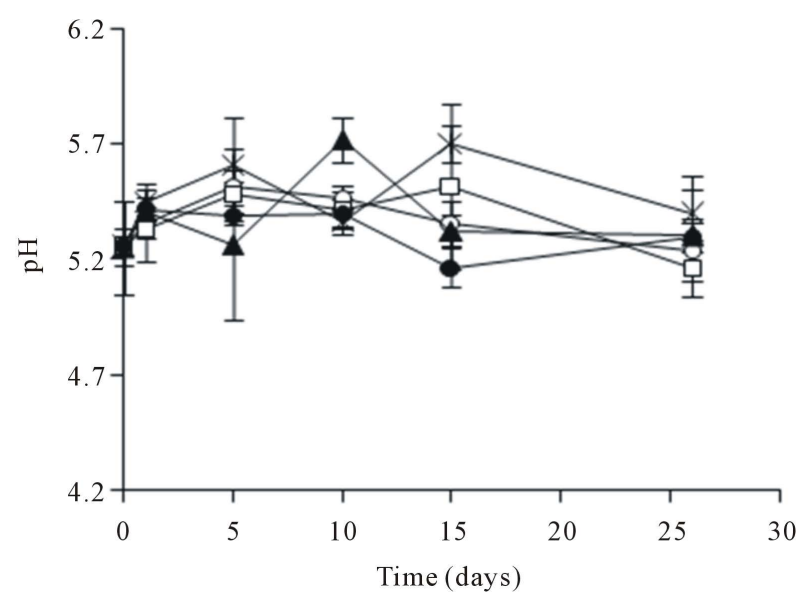

(a)

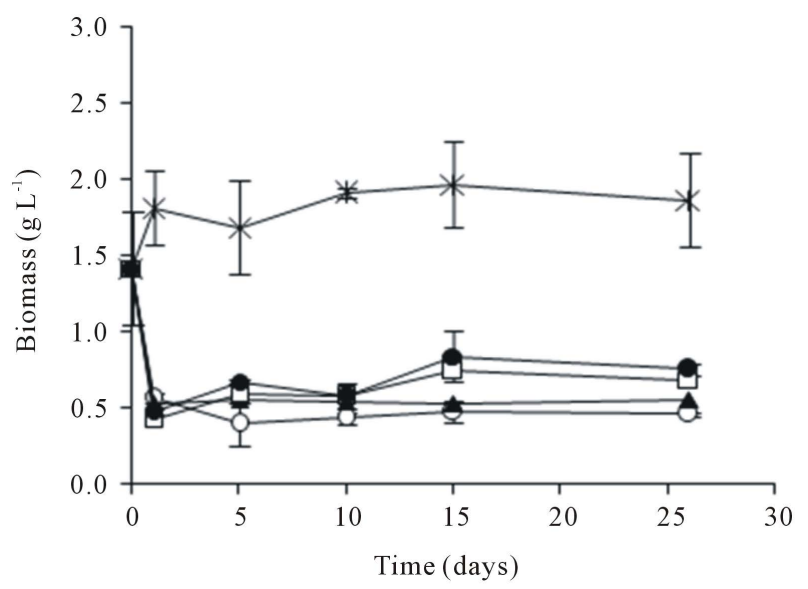

(b)

Figure 3. Profiles of pH (a) and biomass (b) of A. discolor in liquid medium after of the contamination with PCP and addition of SL. Values are expressed as mean of three replicates \pm SD. Where: $(*)$ A. discolor, $(\circ)$ A. discolor + PCP + $0 \mathrm{~g} \mathrm{SL} \cdot \mathrm{L}^{-1},(\Delta)$ A. discolor + PCP + $0.3 \mathrm{~g} \mathrm{SL} \cdot \mathrm{L}^{-1}$, ( $\left.\square\right)$ A. discolor + PCP + $0.6 \mathrm{~g} \mathrm{SL} \cdot \mathrm{L}^{-1},(\bullet)$ A. discolor + PCP + $0.9 \mathrm{~g}$ $\mathrm{SL} \cdot \mathbf{L}^{-1}$.

affected negatively the biomass production of $A$. discolor, diminished until $0.5 \mathrm{~g} \cdot \mathrm{L}^{-1}$, approximately. After 5 days, the fungal biomass increased slowly when the liquid medium was added with SL. Besides, an increase on biomass production was observed with the increase in SL concentration, however was not higher than $0.7 \mathrm{~g} \cdot \mathrm{L}^{-1}$ in presence of $0.9 \mathrm{~g} \cdot \mathrm{L}^{-1}$ of SL, after 26 days of incubation. In contrast, the fungal biomass production was constant in the control assay, without contaminant and without SL, reached a value of $1.9 \mathrm{~g} \cdot \mathrm{L}^{-1}$ after 26 days of culture. Boyle [9] evaluated the effects of three cyclodextrins and PCP on radial growth of the $T$. hirsute. He reported that at $\mathrm{pH} 4.9$ Gamma 8 eliminated the inhibitory effects of $10 \mathrm{mg} \cdot \mathrm{L}^{-1}$ of contaminant and partially overcome those at $50 \mathrm{mg} \cdot \mathrm{L}^{-1}$ Beta $\mathrm{W} 7 \mathrm{M} 1.8$ also alleviated inhibition, but less pronounced. Alpha W6 M1.8 had little effect and 
cyclodextrins did not affect radial growth of T. hirsute. The PCP effects on growth of several white-rot fungi have been well studied. In this context, Tortella et al. [13] studied the tolerance of fungi to mycelia growth in the presence of PCP. They found inhibition mycelia growth when the fungi were exposed at $25 \mathrm{mg} \cdot \mathrm{L}^{-1}$ of PCP. Besides, Walter et al. [47] informed that the most strains of white-rot fungi studied tolerant $20 \mathrm{mg} \cdot \mathrm{L}^{-1}$ of PCP. However, Alleman et al. [48] detected inhibition of growth with 5 - $10 \mathrm{mg} \cdot \mathrm{L}^{-1}$ of PCP for P. chrysosporium, T. versicolor, Inonotus sp, Ganoderma sp. The several responses found could be due to composition of liquid medium and growth conditions [49], PCP doses [44], or fungal strains adapted to PCP [13].

\subsection{Effect of SL on Fungal Surface of A. Discolor Visualized by SEM}

The SEM microscopy was applied on fungal hyphae of $A$. discolor for to detect some SL effect on their surface, such as disruption of cellular membranes or cells lysis. Figure 4 shows SEM images of fungal hyphae with 5 and 20 days of incubation in modified Kirk medium at $\mathrm{pH} 5.5$ and $25^{\circ} \mathrm{C} \pm 2{ }^{\circ} \mathrm{C}$. These images show that $A$. discolor presents septate hyphae (Figure 4(a)) and their conidia are spherical and oval. Spherical conidia have 2.4 $\pm 0.8 \mu \mathrm{m}$ diameters $(\mathrm{n}=5)$ and oval conidia have $3.7 \pm$ $1.2 \mu \mathrm{m}$ long $(\mathrm{n}=5)$. The SEM micrograph shows that SL presents no negative effect on fungal surface of $A$. discolor at the evaluated concentration after 5 and 20-days culture (Figures 4(b) and (c)). Information about the effect of SL on degrading microorganisms is limited. However, Bustamante et al. [30] found that the increase

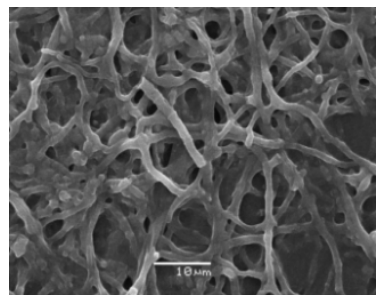

(a)

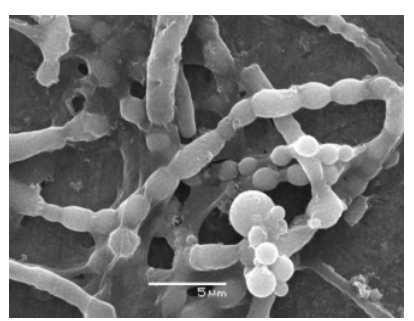

(c)

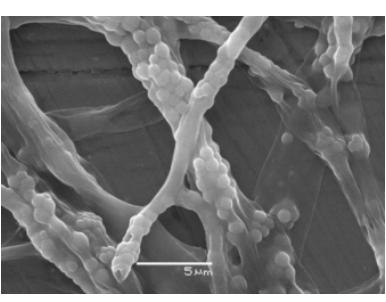

(b) in SL concentration caused an increase in mycelia growth of A. discolor. Besides, Soeder et al. [25] found that SL enhanced growth of the bacteria under all conditions evaluated of surfactant concentrations. Nevertheless, it is known that surfactants can have toxic effect on microorganisms. This negative effect can be related to damage on the cellular membranes or reaction of surfactant with proteins essential to cell functioning, it as was reviewed by Volkering et al. [50]. Garon et al. [36] evaluated the toxicity of three surfactants on several fungal strains. They found that Triton X-100 and Tween 80 were well tolerated by fungi. However, growth inhibition was observed in presence of SDS (sodium dodecyl sulfate). They explained that the low SDS tolerance is possibly due to physic-chemical interactions between surfactants and fungal structures such as membranes and walls. Besides, some studies have shown that charge has a toxic effect; cationic surfactants are more toxic and are applied as antimicrobials, as it has been reviewed by Van Hamme et al. [51].

\section{Conclusion}

In conclusion, it could be said that PCP solubility enhances with increasing SL concentration. Besides, the CMC values decreased when PCP concentration was increased. The biodegradation assay showed a positive SL effect, with high degradation obtained during fungal culture. The SL addition in liquid medium enhanced PCP biodegradation in $18 \%$ with respect to culture control. $A$. discolor does not diminish its ligninolytic activity in presence of PCP and SL, mainly producing MnP. The PCP removal (\%) obtained and the ligninolytic activity, represented by high MnP activity, suggest that SL can be applied to increasing bioavailability and biodegradation of contaminants with low solubility in water. Finally, the SEM micrograph shows that the fungal surface of $A$. discolor was not affected by the SL concentration added to culture medium.

\section{Acknowledgements}

This work was supported by FONDECYT 1090678 and DIUFRO DI10-TD01. We thank Dr. Nelson Duran of Insituto de Química, Biological Chemistry Laboratory, Universidade Estadual de Campinas (UNICAMP), Brazil.

\section{REFERENCES}

[1] M. K. Männisto, M. S. Salinoja-Salonen and J. A. Puhakka, "In Situ Polychlorophenol Bioremediation Potential of the Indigenous Bacterial Community of Boreal Groundwater," Water Research, Vol. 35, No. 10, 2001, pp. 2496-2504.

http://dx.doi.org/10.1016/S0043-1354(00)00527-3 lor after 20 days of incubation in culture medium without SL; (b) and (c) A. discolor after 5 and 20 days of incubation with $0.6 \mathrm{~g} \mathrm{SL} \cdot \mathrm{L}^{-1}$, respectively.
Figure 4. The SEM micrographs of A. discolor. (a) A. disco- 
[2] G. L. Qiao, J. D. Brooks and J. E. Riviere, "Pentachlorophenol Dermal Absorption and Disposition from Soil in Swine: Effects of Occlusion and Skin Microorganism Inhibition," Toxicology and Applied Pharmacology, Vol. 147, No. 2, 1997, pp. 234-246. http://dx.doi.org/10.1006/taap.1997.8288

[3] W. Y. Shiu, K. C. Ma, D. Varhanickova and D. Mackay, "Chlorophenols and Alkylphenols-A Review and Correlation of Environmentally Relevant Properties and Fate in an Evaluative Environment," Chemosphere, Vol. 29, No. 6, 1994, pp. 1155-1224. http://dx.doi.org/10.1016/0045-6535(94)90252-6

[4] M. Cea, J. C. Seaman, A. A. Jara, M. L. Mora and M. C. Diez, "Describing Chlorophenol Sorption on VariableCharge Soil Using the Triple-Layer Model,” Journal of Colloid and Interface Science, Vol. 292, No. 1, 2005, pp.171-178. http://dx.doi.org/10.1016/j.jcis.2005.05.074

[5] US Environmental Protection Agency, "Treatment Technology Performance and Cost Data for Remediation of Wood Preserving Sites,” Cincinnati, OH, 1997.

[6] O. Rubilar, G. Tortella, M. Cea, F. Acevedo, M. Bustamante, L. Gianfreda and M. C. Diez, "Biorremediation of a Chilean Andisol Contaminated with Pentachlorophenol (PCP) by Solid Substrate Cultures of White-rot Fungi," Biodegradation, Vol. 22, No. 1, 2011, pp. 31-41. http://dx.doi.org/10.1007/s10532-010-9373-9

[7] G. V. B. Reddy and M. H. Gold, "Degradation of Pentachlorophenol by Phanerochaete chrysosporium: Intermediates and Reactions Involved," Microbiology, Vol. 146, No. 2, 2000, pp. 405-413.

[8] M. R. Sedarati, T. Keshavarz, A. A. Leontievsky and C. S. Evans, "Transformation of High Concentrations of Chlorophenols by White-Rot Basidiomycete Trametes versicolor Inmobilized on Nylon mesh,” Electronic Journal of Biotechnology, Vol. 6, No. 2, 2003, pp. 104-114.

[9] D. Boyle, "Effects of pH Cyclodextrins on Pentachlorophenol Degradation (Mineralization) by White-Rot Fungi," Journal of Environmental Management, Vol. 80, No. 4, 2006, pp. 380-386.

http://dx.doi.org/10.1016/j.jenvman.2005.09.017

[10] O. Rubilar, G. Feijoo, M. C. Diez, T. A. Lu-Chau, M. T. Moreira and J. M. Lema, "Biodegradation of Pentachlorophenol in Soil Slurry Cultures by Bjerkandera adusta and Anthracophyllum discolor," Industrial \& Engineering Chemistry Research, Vol. 46, No. 21, 2007, pp. 67446751. http://dx.doi.org/10.1021/ie061678b

[11] C. A. Reddy, "The Potential for White-Rot Fungi in the Treatment of Pollutants," Current Opinion in Biotechnology, Vol. 6, No. 3, 1995, pp. 320-328. http://dx.doi.org/10.1016/0958-1669(95)80054-9

[12] I. Eichlerová, L. Homolka, L. Lisá and F. Nerud, “Orange G and Remazol Brilliant Blue R Decolorization by White Rot Fungi Dichomitus squalens, Ischnoderma resinosum and Pleurotus calyptratus," Chemosphere, Vol. 60, No. 3, 2005, pp. 398-404. http://dx.doi.org/10.1016/j.chemosphere.2004.12.036

[13] G. R. Tortella, O. Rubilar, L. Gianfreda, E. Valenzuela and M. C. Diez, "Enzymatic Characterization of Chilean
Native Wood-Rotting Fungi for Potential Use in the Bioremediation of Polluted Environments with Chlorophenols," World Journal of Microbiology and Biotechnology, Vol. 24, No. 12, 2008, pp. 2805-2818.

http://dx.doi.org/10.1007/s11274-008-9810-7

[14] L. Zhu and S. Feng, "Synergistic Solubilization of Polycyclic Aromatic Hydrocarbons by Mixed Anionic-Nonionic Surfactants,” Chemosphere, Vol. 53, No. 5, 2003, pp. 459-467.

http://dx.doi.org/10.1016/S0045-6535(03)00541-1

[15] B. Zhao, L. Zhu, W. Li and B. Chen, "Solubilization and Biodegradation of Phenanthrene in Mixed Anionic-Nonionic Surfactant Solutions," Chemosphere, Vol. 58, No. 1, 2005, pp. 33-40.

http://dx.doi.org/10.1016/j.chemosphere.2004.08.067

[16] Y. Z. Gao, W. T. Ling, L. Z. Zhu, B. W. Zhao and Q. S. Zheng, "Surfactant-Enhanced Phytoremediation of Soil Contaminated with Hydrophobic Organic Contaminants: Potential and Assessment," Pedosphere, Vol. 17, No. 4, 2007, pp. 409-418.

http://dx.doi.org/10.1016/S1002-0160(07)60050-2

[17] C. C. West and J. H. Harwell, "Surfactants and Subsurface Remediation,” Environmental Science \& Technology, Vol. 26, No. 12, 1992, pp. 2324-2330. http://dx.doi.org/10.1021/es00036a002

[18] N. Christofi and I. Ivshina, "Microbial Surfactants and Their Use in Field Studies of Soil Remediation," Journal of Applied Microbiology, Vol. 93, No. 6, 2002, pp. 915929. http://dx.doi.org/10.1046/j.1365-2672.2002.01774.x

[19] D. A. Edwards, R. G. Luthy and Z. Liu, "Solubilization of Polycyclic Aromatic Hydrocarbons in Micellar Nonionic Surfactant Solutions," Environmental Science \& Technology, Vol. 25, No. 1, 1991, pp. 127-133. http://dx.doi.org/10.1021/es00013a014

[20] D. J. L. Prak and P. H. Pritchard, "Solubilization of Polycyclic Aromatic Hydrocarbon Mixtures in Micellar Nonionic Surfactant Solutions,” Water Research, Vol. 36, No. 14, 2002, pp. 3463-3472. http://dx.doi.org/10.1016/S0043-1354(02)00070-2

[21] R.-A. Doong and W.-G. Lei, "Solubilization and Mineralization of Polycyclic Aromatic Hydrocarbons by Pseudomonas putida in the Presence of Surfactant,” Journal of Hazardous Materials, Vol. 96, No. 1, 2003, pp. 15-27. http://dx.doi.org/10.1016/S0304-3894(02)00167-X

[22] K.-H. Shin, K.-W. Kim and Y. Ahn, "Use of Biosurfactant to Remediate Phenanthrene-Contaminated Soil by the Combined Solubilization-Biodegradation Process," Journal of Hazardous Materials, Vol. 137, No. 3, 2006, pp. 1831-1837.

http://dx.doi.org/10.1016/j.jhazmat.2006.05.025

[23] T. L. Cort, M. S. Song and A. Bielefeldt, "Nonionic Effects on Pentachlorophenol Biodegradation," Water Research, Vol. 36, No. 5, 2002, pp. 1253-1261. http://dx.doi.org/10.1016/S0043-1354(01)00320-7

[24] K. Hanna, R. Denoyel, I. Beurroies and J. P. Dubès, “Solubilization of Pentachlorophenol in Micelles and Confined Surfactant Phases," Colloids and Surfaces A: Physicochemical and Engineering Aspects, Vol. 254, No.1-3, 2005, pp. 231-239. 
http://dx.doi.org/10.1016/j.colsurfa.2004.12.016

[25] C. J. Soeder, A. Papaderos, M. Kleespies, H. Kneifel, F. H. Haegel and L. Webb, "Influence of Pythogenic Surfactants (Quillaya Saponin and Soya Lecithin) on BioElimination of Phenanthrene and Fluoranthene by Three Bacteria,” Applied Microbiology and Biotechnology, Vol. 44, No. 5, 1996, pp. 654-659. http://dx.doi.org/10.1007/BF00172499

[26] J. D. Desai and I. M. Banat, "Microbial Production of Surfactants and Their Commercial Potential," Microbiology and Molecular Biology Reviews, Vol. 61, No. 1, 1997, pp. 47-64.

[27] F. Fava and D. Di Gioia, "Soya Lecithin Effects on the Aerobic Biodegradation of Polychlorinated Biphenyls in an Artificially Contaminated Soil," Biotechnology and Bioengineering, Vol. 72, No. 2, 2001, pp. 177-184. http://dx.doi.org/10.1002/1097-0290(20000120)72:2<177 $\because$ AID-BIT6>3.0.CO;2-K

[28] A. Singh, J. D. Van Hamme and O. P. Ward, "Surfactants in Microbiology and Biotechnology: Part 2. Application Aspects,” Biotechnology Advances, Vol. 25, No. 1, 2007, pp. 99-121.

http://dx.doi.org/10.1016/j.biotechadv.2006.10.004

[29] A. Flasz, C. A. Rocha, B. Mosquera and C. Sajo, “A Comparative Study of the Toxicity of a Synthetic Surfactant and One Produced by Pseudomonas aeruginosa ATCC 55925,” Medical Science Research, Vol. 26, No. 3, 1998, pp. 181-185.

[30] M. Bustamante, M. E. González, A. Cartes and M. C. Diez, "Effect of Soya Lecithin on the Enzymatic System of the White-Rot Fungi Anthracophyllum discolor," Journal of Industrial Microbiology \& Biotechnology, Vol. 38, No. 1, 2011, pp. 189-197.

http://dx.doi.org/10.1007/s10295-010-0844-0

[31] M. Tien and T. K. Kirk, "Lignin Peroxidase of Phanerochaete chrysosporium," Methods in Enzymology, Vol. 161, 1988, pp. 238-249. http://dx.doi.org/10.1016/0076-6879(88)61025-1

[32] E. deJong, A. E. Cazemier, J. A. Field and J. A. M. de Bont, "Physiological Role of Chlorinated Aryl Alcohols Biosynthesized De Novo by the White Rot Fungus Bjerkandera sp. Strain BOS55,” Applied and Environmental Microbiology, Vol. 60, No. 1, 1994, pp. 271-277.

[33] M. D. P. Castillo, P. Ander and J. Stenström, “Lignin and Manganese Peroxidase Activity in Extracts from Straw Solid Substrate Fermentations," Biotechnology Techniques, Vol. 11, No. 9, 1997, pp. 701-706. http://dx.doi.org/10.1023/A:1018423829918

[34] K. Eddouaouda, S. Mnif, A. Badis, S. Ben Younes, S. Cherif, S. Ferhat, N. Mhiri, M. Chamkha and S. Sayadi, "Characterization of a Novel Biosurfactant Produced by Staphylococcus sp. Strain 1E with Potential Application on Hydrocarbon Bioremediation," Journal of Basic Microbiology, Vol. 52, No. 4, 2012, pp. 408-418. http://dx.doi.org/10.1002/jobm.201100268

[35] J.-L. Li and B.-H. Chen, "Surfactant-Mediated BioDegradation of Polyciclic Aromatic Hydrocarbons," Materials, Vol. 2, No. 1, 2009, pp. 76-94.

http://dx.doi.org/10.3390/ma2010076
[36] D. Garon, S. Krivobok, D. Wouessidjewe and F. SeigleMurandi, "Influence of Surfactants on Solubilization and Fungal Degradation of Fluorine,” Chemosphere, Vol. 47, No. 3, 2002, pp. 303-309. http://dx.doi.org/10.1016/S0045-6535(01)00299-5

[37] N. K. Bordoli and B. K. Konwar, "Bacterial Biosurfactant in Enhancing Solubility and Metabolism of Petroleum Hydrocarbons," Journal of Hazardous Materials, Vol. 170, No. 1, 2009, pp. 495-505.

http://dx.doi.org/10.1016/j.jhazmat.2009.04.136

[38] K. Nesměrák and I. Němcová, "Determination of Critical Micelle Concentration by Electrochemical Means," Analytical Letters, Vol. 39, No. 6, 2006, pp. 1023-1040. http://dx.doi.org/10.1080/00032710600620302

[39] E. Fuguet, C. Ràfols, M. Rosés and E. Bosch, "Critical Micelle Concentration of Surfactants in Aqueous Buffered and Unbuffered Systems," Analytica Chimica Acta, Vol. 548, No. 1-2, 2005, pp. 95-100. http://dx.doi.org/10.1016/j.aca.2005.05.069

[40] P. A. Hassan and J. V. Yakhmi, "Growth of Cationic Micelles in the Presence of Organic Additives,” Langmuir, Vol. 16, No. 18, 2000, pp. 7187-7191. http://dx.doi.org/10.1021/la000517o

[41] D. G. Choi, W. J. Kim and S. M. Yang, "Shear-Induced Microestructure and Rheology of Cetylpyridinium Chloride/Sodium Salicylate Micellar Solutions,” Korea-Australia Rheology Journal, Vol. 12, No. 3-4, 2000, pp. 143149.

[42] M. Abu-Hamdiyyah, "Amphiphilic Coaggregation with Cetyltrimethylammonium Bromide,” The Journal of Physical Chemistry, Vol. 90, No. 7, 1986, pp. 1345-1349. http://dx.doi.org/10.1021/j100398a027

[43] G. J. Mileski, J. A. Bumpus, M. A. Jurek and S. D. Aust, "Bioegradation of Pentachlorophenol by the White Rot Fungus Phanerochaete chrysosporium," Applied and Environmental Microbiology, Vol. 54, No. 12, 1988, pp. 2885-2889.

[44] B. C. Alleman, B. E. Logan and R. L. Gilbertson, “Toxicity of Pentachlorophenol to Six Species of White Rot Fungi as a Function of Chemical Dose," Applied and Environmental Microbiology, Vol. 58, No. 12, 1992, pp. 4048-4050.

[45] S. K. Park and A. R. Bielefeldt, “Aqueous Chemistry and Interactive Effects on Non-Ionic Surfactant and Pentachlorophenol Sorption to Soil," Water Research, Vol. 37, No. 19, 2003, pp. 4663-4672.

http://dx.doi.org/10.1016/j.watres.2003.08.005

[46] M. J. van der Werf, S. Hartmans and W. J. J. van den Tweel, "Permeabilization and Lysis of Pseudomonas pseudoalcaligenes Cells by Triton X-100 for Efficient Production of D-malate,” Applied Microbiology and Biotechnology, Vol. 43, No. 4, 1995, pp. 590-594. http://dx.doi.org/10.1007/BF00164759

[47] M. Walter, J. Guthrie, S. Sivakumaran, E. Parker, A. Slade, D. McNaughton and K. Boyd-Wilson, "Screening of New Zealand Native White-Rot Isolates for PCP Degradation,” Bioremediation Journal, Vol. 7, No. 2, 2003, pp. $119-128$

http://dx.doi.org/10.1080/713607977 
[48] B. C. Alleman, B. E. Logan and R. L. Gilbertson, “A Rapid Method to Screen Fungi for Resistance to Toxic Chemicals,” Biodegradation, Vol. 4, No. 2, 1993, pp. 125129. http://dx.doi.org/10.1007/BF00702329

[49] A. Mendoza-Cantú, A. Albores, L. Fernández-Linares and R. Rodríguez-Vazquez, "Pentachlorophenol Biodegradation and Detoxification by the White-rot Fungus Phanerochaete chrysosporium," Environmental Toxicology, Vol. 15, No. 2, 2000, pp. 107-113.

http://dx.doi.org/10.1002/(SICI)1522-7278(2000)15:2<10

\section{7::AID-TOX6>3.0.CO;2-K}

[50] F. Volkering, A. M. Breure and W. H. Rulkens, "Microbiological Aspects of Surfactant Use for Biological Soil Remediation,” Biodegradation, Vol. 8, No. 6, 1998, pp. 401-417. http://dx.doi.org/10.1023/A:1008291130109

[51] J. D. Van Hamme, A. Singh and O. P. Ward, "Physiological Aspects. Part 1 in a Series of Papers Devoted to Surfactants in Microbiology and Technology," Biotechnology Advances, Vol. 24, No. 6, 2006, pp. 604-620. http://dx.doi.org/10.1016/j.biotechadv.2006.08.001 